\title{
Subcapsular Hematoma After Ureteroscopy and Laser Lithotripsy
}

\author{
Peter Ka-Fung Chiu, MRCSEd, Chun-Ki Chan, MRCSEd, Wai-kit Ma, FRCSEd(urol), \\ Kim-Chung To, FRCSEd(urol), Fu-Keung Cheung, FRCSEd(urol), and Ming-kwong Yiu, FRCSEd(urol)
}

\begin{abstract}
Background and Purpose: Renal hematoma after ureteroscopic lithotripsy (URSL) using holmium:yttriumaluminum-garnet (Ho:YAG) laser is a rare complication. We aimed to review our center's experience of post-URSL subcapsular hematoma.

Patients and Methods: From 2007 to 2012, 1114 URSLs using 7.5F semi-rigid ureteroscopes were performed. Patients with post-URSL symptomatic renal hematoma were reviewed. Perioperative information on patients' preoperative morbidity, renal function, stone characteristics, and degree of hydronephrosis were reviewed. Operative information, postoperative presentation of symptoms, changes in blood parameters, CT findings, and subsequent management were documented.

Results: Post-URSL subcapsular hematoma was diagnosed in 4 of $1114(0.36 \%)$ patients, who ranged in age from 43 to 63 years. Preoperative imaging showed that all four patients had obstructing proximal ureteral stones ranging in size from 0.7 to $2.1 \mathrm{~cm}$, and three of them had thin renal cortices. Pressure bags were not used, and Double-J ureteral stents were inserted in all cases. All four patients had the triad of loin pain, fever, and significant hemoglobin drop necessitating transfusion. Three patients presented within 2 days of URSL, and one patient presented on day 20. One patient was treated conservatively and recovered with bed rest and antibiotics. Urgent angiography was performed on one patient in view of a significant drop in hemoglobin, but no embolization was needed. One patient underwent ultrasonography-guided drainage of the hematoma, and another had an emergency open clot evacuation because of significant compression on the kidney by the hematoma. Follow-up CT scans confirmed the resolution of the hematoma in all cases.

Conclusions: Post-URSL subcapsular hematoma is a rare but potentially serious complication. A high index of suspicion is needed when patients present with significant loin pain and fever after URSL for obstructing proximal ureteral stones with thin renal cortices. The management of post-URSL subcapsular hematomas needs to be customized for each patient.
\end{abstract}

\section{Introduction}

$\mathbf{U}$ RETEROSCOPIC LITHOTRIPSY (URSL) with holmium: yttrium-aluminum-garnet (Ho:YAG) laser is effective and safe for managing ureteral stones, ${ }^{1}$ and is one of the most common procedures in urology. Given the development of smaller caliber ureteroscopes and the refinement of endoscopic techniques, complication rates are generally regarded as low. Major complications occur in fewer than $0.1 \%$ of cases. $^{2}$ Among the major complications, renal hematoma after URSL has only been reported in two case reports and one case series. ${ }^{3-5}$ Nuttall and associates ${ }^{2}$ reviewed 48 studies on URSL complications that covered 4454 URSLs and found only one case of perinephric hematoma.

We believe that more attention to this rare but potentially serious complication is warranted. Consequently, we con- ducted a detailed analysis of our cases of subcapsular and perinephric hematoma after URSL with Ho:YAG laser. The presentation, common characteristics, and customized management of each case are discussed.

\section{Patients and Methods}

All URSLs performed in our center from January 2007 to March 2012 were retrospectively reviewed, and cases with post-URSL subcapsular hematoma were identified and studied in detail. Patient demographics, stone characteristics on CT or intravenous urography (IVU), the presence of hydronephrosis, intraoperative findings, presentation of renal hematoma, and treatment of each patient were documented and compared.

URSL was performed with a 7.5F semi-rigid nonirrigating ureteroscope under general anesthesia. A 0.035-inch Terumo

Department of Surgery, Princess Margaret Hospital, Hong Kong. 
safety guidewire and an $8 \mathrm{~F}$ infant feeding tube for bladder drainage were used in every case. The ureteroscope was introduced into the ureter without dilation under direct vision and/or fluoroscopic guidance. The irrigating saline solution was positioned $80 \mathrm{~cm}$ above the patient. A $0.365 \mu \mathrm{m}$ Ho:YAG laser fiber was used for lithotripsy, and the energy setting was set at 0.6 to $1.0 \mathrm{~J}$ at a rate of 6 to $10 \mathrm{~Hz}$. Laser fragmentation of stones was performed until they were in 1-2 mm fragments. A $6 \mathrm{~F}$ or $7 \mathrm{~F}$ Double-J stent was inserted and kept in for 4 to 6 weeks most of the time, according to the decision of the surgeon. Patients without fever or loin pain were usually discharged within 24 to 36 hours after the procedure.

For patients with persistent fever or loin pain or necessitating readmission, continued antibiotic therapy and close monitoring were enforced. If accompanied by a concomitant drop in hemoglobin not attributable to other causes, the pain and fever were suspected to be procedure-related and CT urography with contrast was performed to confirm the diagnosis of renal hematoma. Individualized treatment was adopted according to the patient's vital signs and response to medical therapy.

\section{Results}

Of the 1114 URSLs performed in the 5-year period, 4 $(0.36 \%)$ cases of subcapsular hematoma were identified (Table 1). The four patients were two men and two women between 43 and 63 years of age. Three of the patients were obese with a body mass index $(\mathrm{BMI})>25 \mathrm{~kg} / \mathrm{m}^{2}$. The serum creatinine level before URSL was normal in three patients and mildly impaired in one $(158 \mu \mathrm{mol} / \mathrm{L})$. Preoperative serum platelet level and International Normalized Ratio were all normal. No patient was receiving antiplatelet or anticoagulant medication. Regarding the stone characteristics, all were radiopaque obstructive upper ureter stones ranging from 0.7 to $2.1 \mathrm{~cm}$, associated with mild to severe hydronephrosis. Fever, loin pain, and a significant drop in hemoglobin level ( $3-5 \mathrm{~g} / \mathrm{dL})$ were the presenting symptoms in all four patients, and all of

Table 1. Clinical Details of the Four Patients with Postureteroscopic Lithotripsy Renal Hematomas

\begin{tabular}{|c|c|c|c|c|}
\hline & Patient 1 & Patient 2 & Patient 3 & Patient 4 \\
\hline Age/sex & $63 / \mathrm{M}$ & $50 / \mathrm{F}$ & $63 / F$ & $43 / \mathrm{F}$ \\
\hline BMI & 27.3 & 22.7 & 27.2 & 39.3 \\
\hline Medical history & $\begin{array}{l}\text { Hypertension, bilateral } \\
\text { renal stones, prostate } \\
\text { cancer pending } \\
\text { prostatectomy }\end{array}$ & Good past health & $\begin{array}{l}\text { Hypertension, } \\
\text { diabetes }\end{array}$ & $\begin{array}{l}\text { Hyperlipidemia, } \\
\text { asthma, } \\
\text { endometriosis }\end{array}$ \\
\hline $\begin{array}{l}\text { Baseline serum } \\
\text { creatinine } \\
(\mu \mathrm{mol} / \mathrm{L})\end{array}$ & $66^{x}$ & 158 & 70 & 69 \\
\hline Location & Proximal (left) & Proximal (right) & Proximal (right) & Proximal (right) \\
\hline Size & $1.5 \mathrm{~cm}$ & $2.1 \mathrm{~cm}$ & $2.1 \mathrm{~cm}$ & $0.7 \mathrm{~cm}$ \\
\hline Hydronephrosis & Severe & Severe & Severe & Mild \\
\hline Renal cortex & Thin & Thin $1 \mathrm{~cm}$ & Thin $1 \mathrm{~cm}$ & Normal $2.8 \mathrm{~cm}$ \\
\hline $\begin{array}{l}\text { Procedure } \\
\text { duration }\end{array}$ & $150 \mathrm{~min}$ & $95 \mathrm{~min}$ & $66 \mathrm{~min}$ & $30 \mathrm{~min}$ \\
\hline $\begin{array}{l}\text { Double-J stent } \\
\text { size }\end{array}$ & F 7 & F 7 & F 6 & F 6 \\
\hline Residual stone & Stone clearance & $1 \mathrm{~cm}$ renal stone & Multiple renal stones & $5 \mathrm{~mm}$ renal stone \\
\hline $\begin{array}{l}\text { Intraoperative } \\
\text { findings }\end{array}$ & $\begin{array}{l}\text { Tight ureteral orifice } \\
\text { and tortuous ureter }\end{array}$ & $\begin{array}{l}\text { Tightly impacted } \\
\text { stone }\end{array}$ & $\begin{array}{l}\text { Tortuous ureter and } \\
\text { tightly impacted } \\
\text { stone }\end{array}$ & $\begin{array}{l}\text { Tortuous ureter, o } \\
\text { ureteral stone seen }\end{array}$ \\
\hline Presentation day & Day 1 & Day 2 & Day 2 & Day 20 \\
\hline $\begin{array}{l}\text { Postoperative } \\
\text { presentation }\end{array}$ & $\begin{array}{l}\text { Hematuria, loin pain, } \\
\text { fever }\end{array}$ & Fever, loin pain & Fever, loin pain & Fever, loin pain \\
\hline $\mathrm{CT}$ findings & $\begin{array}{l}10.5 \times 5.5 \times 18 \mathrm{~cm} \\
\text { subcapsular } \\
\text { hematoma }\end{array}$ & $\begin{array}{l}2.6 \times 8.2 \times 10 \mathrm{~cm} \\
\text { subcapsular } \\
\text { hematoma }\end{array}$ & $\begin{array}{l}7 \times 9.5 \times 11 \mathrm{~cm} \\
\text { subcapsular } \\
\text { hematoma }\end{array}$ & $\begin{array}{l}20 \times 10 \times 10 \mathrm{~cm} \\
\text { subcapsular } \\
\text { hematoma }\end{array}$ \\
\hline $\begin{array}{l}\text { Hb drop from } \\
\text { baseline }\end{array}$ & $4.4 \mathrm{~g} / \mathrm{dL}$ & $3 \mathrm{~g} / \mathrm{dL}$ & $5 \mathrm{~g} / \mathrm{dL}$ & $5 \mathrm{~g} / \mathrm{dL}$ \\
\hline $\begin{array}{l}\text { Packed cells } \\
\text { transfusion }\end{array}$ & 2 units & 2 units & 2 units & 2 units \\
\hline Progress & $\begin{array}{l}\text { Fever and symptom } \\
\text { subside }\end{array}$ & Persistent fever & Further drop of $\mathrm{Hb}$ & Potential Page kidney \\
\hline Management & Conservative & $\begin{array}{l}\text { Ultrasonography } \\
\text { guided drainage of } \\
10 \mathrm{~mL} \text { hematoma }\end{array}$ & $\begin{array}{l}\text { Angiogram: No } \\
\text { significant contrast } \\
\text { extravasation; no } \\
\text { embolization done }\end{array}$ & $\begin{array}{l}\text { Open evacuation of } \\
500 \mathrm{~mL} \text { hematoma }\end{array}$ \\
\hline Hospital stay & 14 days & 13 days & 12 days & 59 days \\
\hline Creatinine on FU & 70 & 182 & 66 & 71 \\
\hline
\end{tabular}

$\mathrm{BMI}=$ body mass index; $\mathrm{CT}=$ computed tomography; $\mathrm{Hb}=$ hemoglobin; $\mathrm{FU}=$ follow-up. 
them needed blood transfusion and continued antibiotic therapy. Three patients presented early, within 2 days after URSL, while one had a delayed presentation on day 20. The three patients who presented early all had a thin renal cortex, impacted ureteral stone, tortuous ureter, and prolonged operation lasting more than 60 minutes. A flexible ureteroscope was used in one patient because of the tortuosity of the ureter.

The treatment plan for all patients differed according to their clinical situation. Patient 1 was treated conservatively with antibiotics and bed rest because he remained hemodynamically stable with a static hemoglobin level after the initial drop, and no active contrast extravasation was depicted on CT. Patient 2 (Fig. 1) had persistent fever, and a pigtail drain was inserted to drain the subcapsular hematoma under ultrasonography guidance on day 8 . Her fever subsided soon after drainage, and she was discharged on day 12. A followup CT scan at 5 weeks showed complete resolution of the hematoma. Patient 3 had a further drop in hemoglobin level after confirmation of the subcapsular hematoma on CT. Urgent angiography was performed, which revealed no significant contrast extravasation, and embolization was not performed.

Patient 4 had delayed presentation and was readmitted for fever and loin pain on day 20. Blood tests revealed a $5 \mathrm{~g} / \mathrm{dL}$ drop in serum hemoglobin level compared with the preoperative level. A CT scan showed significant compression of the kidney by a hematoma measuring $20 \times 10 \times 10 \mathrm{~cm}$ (Fig. 2). With the concern of a Page kidney, open evacuation of the hematoma was performed, and $500 \mathrm{~mL}$ of blood clots were evacuated. Follow-up CT after 3 weeks showed a small perinephric abscess, and ultrasonography-guided aspiration was performed. A subsequent CT 2 months later confirmed the resolution of perinephric collection.

The three patients without need of open surgery were discharged within 2 weeks, while the patient with open

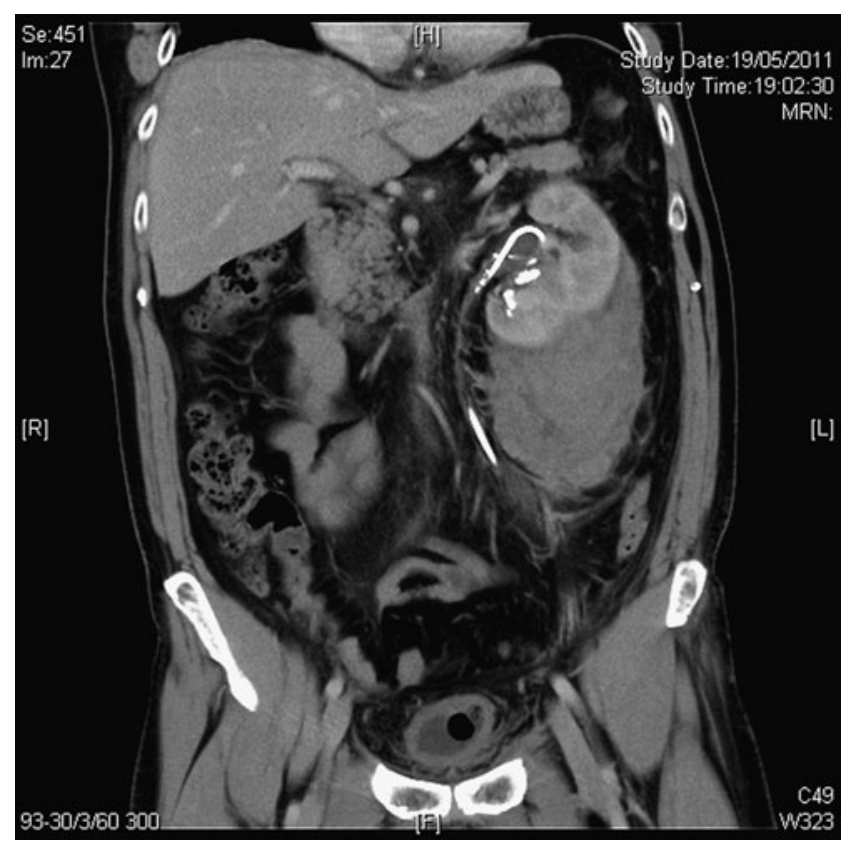

FIG. 1. Patient with ultrasonography-guided drainage of hematoma performed.

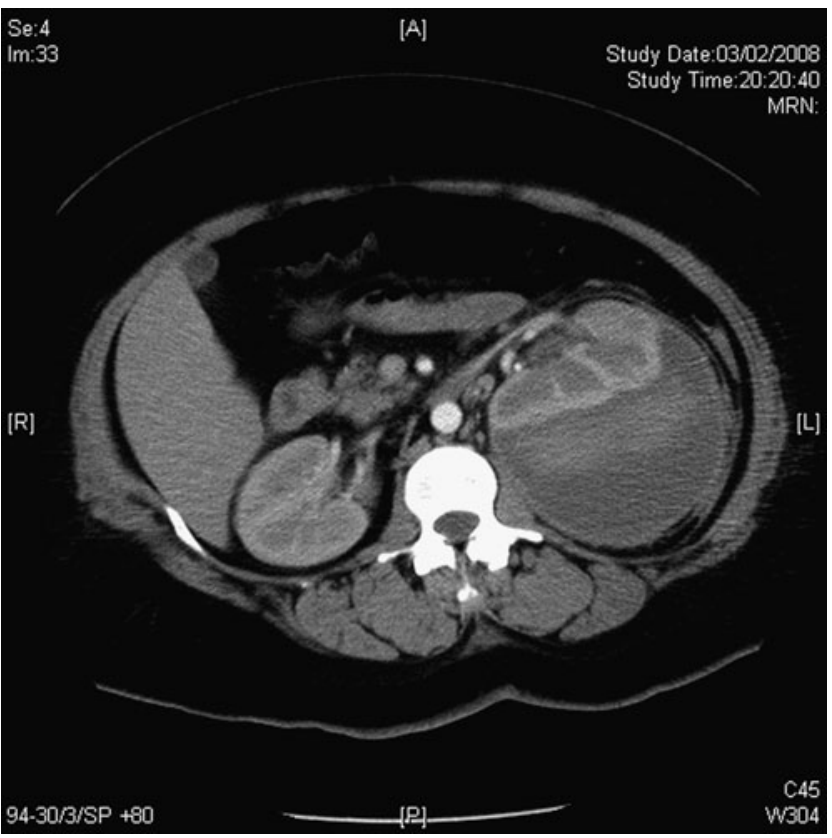

FIG. 2. Patient with open evacuation of hematoma for potential Page kidney

evacuation stayed for almost 2 months. All four patients recovered well with no significant deterioration in renal function, and all hematomas had resolved by the time of the follow-up scans.

\section{Discussion}

While subcapsular hematoma has been thoroughly studied and reported as a complication after extracorporeal shockwave lithotripsy (SWL), its occurrence is far less common after URSL. Despite its rare occurrence, this disease warrants particular attention because it has potentially serious sequelae for kidney function and can easily be missed if a high index of suspicion is not maintained. This article describes the presentation and management of our series of four rare cases of renal hematoma after URSL. The overall incidence of $0.36 \%$ in our series was very similar to the other case series recently reported in Wuhan, China. ${ }^{3}$ In their series, Bai and colleagues ${ }^{3}$ reported $11(0.4 \%)$ subcapsular hematomas after 2848 URSLs using the Ho:YAG laser, and described the risk factors for the development of hematoma. To the best of our knowledge, ours is the second series in the English-language literature after that of Bai and colleagues. ${ }^{3}$ Table 2 summarizes the published reports on subcapsular hematoma after URSL.

The presentation of subcapsular hematoma after URSL is similar to that after SWL. All four of our patients presented with loin pain and fever. In the two single case reports ${ }^{4,5}$ and the series by Bai and coworkers, ${ }^{3}$ the chief complaint was loin pain. Most patients also presented with fever and a palpable loin mass. Other associated symptoms included hematuria, diffuse abdominal pain, and hypotension. Because patients undergoing uneventful URSL are expected to recover quickly and become ambulatory within a day of the procedure, these signs and symptoms should alert the attending physician to look for any signs of serious complications. Differential diagnoses would include sepsis, incomplete stone 
Table 2. Summary of Published Reports on Subcapsular Hematoma After Ureteroscopic Lithotripsy

\begin{tabular}{|c|c|c|c|c|}
\hline & Duffey $2008^{5}$ & Bansal $2010^{4}$ & Bai $2011^{3}$ & Current study \\
\hline Number of patients & 1 & 1 & 11 & 4 \\
\hline Age/sex & $19 /$ male & $35 /$ male & Mean $44 / 82 \%$ male & Mean $55 / 25 \%$ male \\
\hline BMI & / & / & Median 24.7 & Mean 29.1 \\
\hline Ureteral stone location & Proximal & Proximal & $\begin{array}{l}\text { Proximal } 21 \% \\
\text { Middle: } 29 \% \\
\text { Distal: } 50 \%\end{array}$ & Proximal 100\% \\
\hline Mean stone size (range) & $0.5 \mathrm{~cm}$ & $1.0 \mathrm{~cm}$ & $1.4 \mathrm{~cm}$ & $1.6 \mathrm{~cm}$ \\
\hline Hydronephrosis & Moderate & Moderate & $\begin{array}{l}8 \% \text { mild } \\
25 \% \text { moderate } \\
67 \% \text { severe }\end{array}$ & $\begin{array}{l}25 \% \text { mild } \\
75 \% \text { severe }\end{array}$ \\
\hline Operative time range & / & / & Range $32-50 \mathrm{~min}$ & Range $30-150 \mathrm{~min}$ \\
\hline Irrigation pressure & / & / & $239 \mathrm{cmH}_{2} \mathrm{O}$ & $80 \mathrm{cmH}_{2} \mathrm{O}$ \\
\hline Presentation time & $<12$ hours & 12 hours & 4-10 hours & $\begin{array}{l}3 \text { patients from day } 1-2 \\
1 \text { patient on day } 20\end{array}$ \\
\hline Presenting symptoms & $\begin{array}{l}\text { Loin pain, } \\
\text { vomiting }\end{array}$ & Loin pain, fever & $\begin{array}{l}\text { Loin pain, } \\
\text { hematuria, fever, } \\
\text { hypotension }\end{array}$ & Loin pain, fever, hematuria \\
\hline $\mathrm{Hb}$ drop from baseline & $2.2 \mathrm{~g} / \mathrm{dL}$ & / & / & $3-5 \mathrm{~g} / \mathrm{dL}$ \\
\hline Packed cells transfusion & 0 unit & 0 unit & $\begin{array}{l}\text { Mean } 2.8 \text { units } \\
\text { (range } 2-4 \text { ) }\end{array}$ & 2 units in all patients \\
\hline Management & Conservative & $\begin{array}{l}\text { Percutaneous } \\
\text { nephrostomy and } \\
\text { percutaneous } \\
\text { drainage of } \\
\text { hematoma }\end{array}$ & $\begin{array}{l}3 \text { conservative } \\
6 \text { percutaneous } \\
\text { drainage } \\
2 \text { open drainage }\end{array}$ & $\begin{array}{l}1 \text { Conservative } \\
1 \text { Angiogram } \\
1 \text { Percutaneous drainage } \\
1 \text { Open drainage }\end{array}$ \\
\hline Hospital stay & 2 days & 9 days & 10-35 days & 12-59 days \\
\hline
\end{tabular}

$\mathrm{BMI}=$ body mass index; $\mathrm{Hb}=$ hemoglobin.

fragmentation with persistent obstruction, or subcapsular hematoma. The presence of a significant hemoglobin drop would strongly suggest the diagnosis of subcapsular hematoma.

The etiology underlying the complication of subcapsular hematoma has not been well defined. Bansal and associates ${ }^{4}$ suggested that the most probable explanation for the development of hematoma could be trauma to the pelvicaliceal system during guidewire manipulation, or raised intrarenal pressure leading to forniceal rupture and separation of the capsule from the parenchyma and hematoma. Bai and coworkers $^{3}$ showed that larger stone size $(1.4$ vs $0.9 \mathrm{~cm})$, more severe ipsilateral hydronephrosis, longer operation duration (41 vs $33 \mathrm{~min}$ ), and higher perfusion pressure of hydraulic irrigation (176.8 vs $170.2 \mathrm{~mm} \mathrm{Hg}$ ) were risks factors associated with subcapsular hematoma formation.

Although our small case number rendered statistical correlation unsound, some extra clues can be provided. All of our patients had obstructing proximal upper ureteral stones and three of the affected kidneys were associated with thin renal cortices. Long-term obstruction from the stone can result in several technical challenges to the operation: (1) A more tortuous ureter distal to the obstruction site, making it difficult to advance the guidewire and increasing the risk of injury; (2) the angulation of the ureter at the stone obstruction site can hinder the advancement of the ureteroscope, and a higher perfusion pressure through manual or mechanical pumping is often needed to visualize the lumen; (3) a dilated pelvicaliceal system with a reduced cortical thickness reduces the resistance to raised intrarenal pressure and renders the capsule more susceptible to injury.
This echoes the postulation of forniceal rupture by Bansal and colleagues, ${ }^{4}$ and the observation of a forniceal rupture during open exploration by Bai and associates. ${ }^{3}$ Bai and associates ${ }^{3}$ proposed that the post-URSL release of intrarenal pressure could lead to sudden expansion and rupture of the compressed renal parenchyma and vessels, causing bleeding and hematoma formation within the renal capsule. ${ }^{3}$ This effect may be more prominent when the capillaries are thin or even torn off to varying degrees in hydronephrotic kidneys. ${ }^{6}$ In our series, the same hydrostatic pressure of $80 \mathrm{~cm} \mathrm{H}_{2} \mathrm{O}$ was adopted for all patients, and no machine pumps were applied, although there were variations in the irrigating pressure provided by manual pressure. The current evidence suggests that maintaining a steady and low intrarenal pressure is a prerequisite to avoid intrarenal reflux and injury to the fornices. From our series, we suggest that extra care should be taken to prevent high irrigating pressure in patients with proximal ureteral stones with significant hydronephrosis and a thin renal cortex.

Three of our four patients were obese, with a BMI $>25 \mathrm{~kg} /$ $\mathrm{m}^{2}$. This may cause increased difficulty in guidewire placement and ureteroscope advancement, thus increasing the chance of injury to the system. Although the study by Bai and coworkers $^{3}$ did not show BMI as a risk factor for subcapsular hematoma formation, we propose that caution should be taken in handling ureteroscopes in obese patients.

There is no standardized management of subcapsular hematoma after URSL, as there is for hematomas occurring after SWL. Management was tailored according to each patient's clinical condition, mass effect of the hematoma, and clinical progress with medical therapy, which were different in all 
patients in our series. In the 11 patients in the series by Bai and colleagues, ${ }^{3} 3$ patients were treated conservatively, 6 patients were treated with percutaneous drainage, and 2 patients had open evacuation of the hematoma and repair of the ruptured calix within a day of presenting with subcapsular hematoma. There is no available protocol for the ideal timing of surgical intervention, because the indication varies with the individual condition. We suggest that for patients who present with significant loin pain with or without fever after URSL, the serum hemoglobin level should be monitored for any significant drop, and CT urographt should be performed if there is any suspicion of hematoma development. Management of post-URSL hematoma should include conservative, imageguided drainage of the hematoma, angiography, embolization, and finally open drainage as a last resort.

\section{Conclusions}

Post-URSL subcapsular hematoma is a rare but potentially serious complication. A high index of suspicion is needed when patients present with significant loin pain and fever after URSL for obstructing proximal ureteral stones with thin renal cortices. Management of post-URSL subcapsular hematomas needs to be customized for each patient.

\section{Disclosure Statement}

No competing financial interests exist.

\section{References}

1. Seitz C, Tanovic E, Kikic Z, Fajkovic H. Impact of stone size, location, composition, impaction, and hydronephrosis on the efficacy of holmium:YAG-laser ureterolithotripsy. Eur Urol 2007;52:1751-1757.
2. Nuttall MC, Abbaraju J, Dickinson IK, et al. A review of studies reporting on complications of upper urinary tract stone ablation using the holmium:YAG laser. Br J Med Surg Urol 2010;3:151-159.

3. Bai J, Li C, Wang S, et al. Subcapsular renal haematoma after holmium:yttrium-aluminum-garnet laser ureterolithotripsy. BJU Int 2012;109:1230-1234.

4. Bansal U, Sawant A, Dhabalia J. Subcapsular renal hematoma after ureterorenoscopy: An unknown complication of a known procedure. Urol Ann 2010;2:119-121.

5. Duffey BG, Lee JY, Monga M. Perinephric hematoma following ureteroscopy and holmium laser lithotripsy. Open Urol Nephrol J 2008;1:36-37.

6. Ninomiya $H$, Inomata $T$, Ogihara K. Microvasculature of hydronephrotic kidneys in KK-A(Y) mice. J Vet Med Sci 2000; 62:1093-1098.

Address correspondence to: Wai-kit Ma, FRCSEd(urol) Department of Surgery Princess Margaret Hospital Hong Kong

E-mail: kitkitma@yahoo.com

$$
\begin{aligned}
& \text { Abbreviations Used } \\
\mathrm{BMI} & =\text { body mass index } \\
\mathrm{CT} & =\text { computed tomography } \\
\mathrm{Ho}: \mathrm{YAG} & =\text { holmium: yttrium-aluminum-garnet } \\
\mathrm{IVU} & =\text { intravenous urography } \\
\mathrm{SWL} & =\text { shockwave lithotripsy } \\
\mathrm{URSL} & =\text { ureteroscopic lithotripsy }
\end{aligned}
$$

